\title{
Deglobalisation post COVID-19 could spell trouble for the European Monetary Union
}

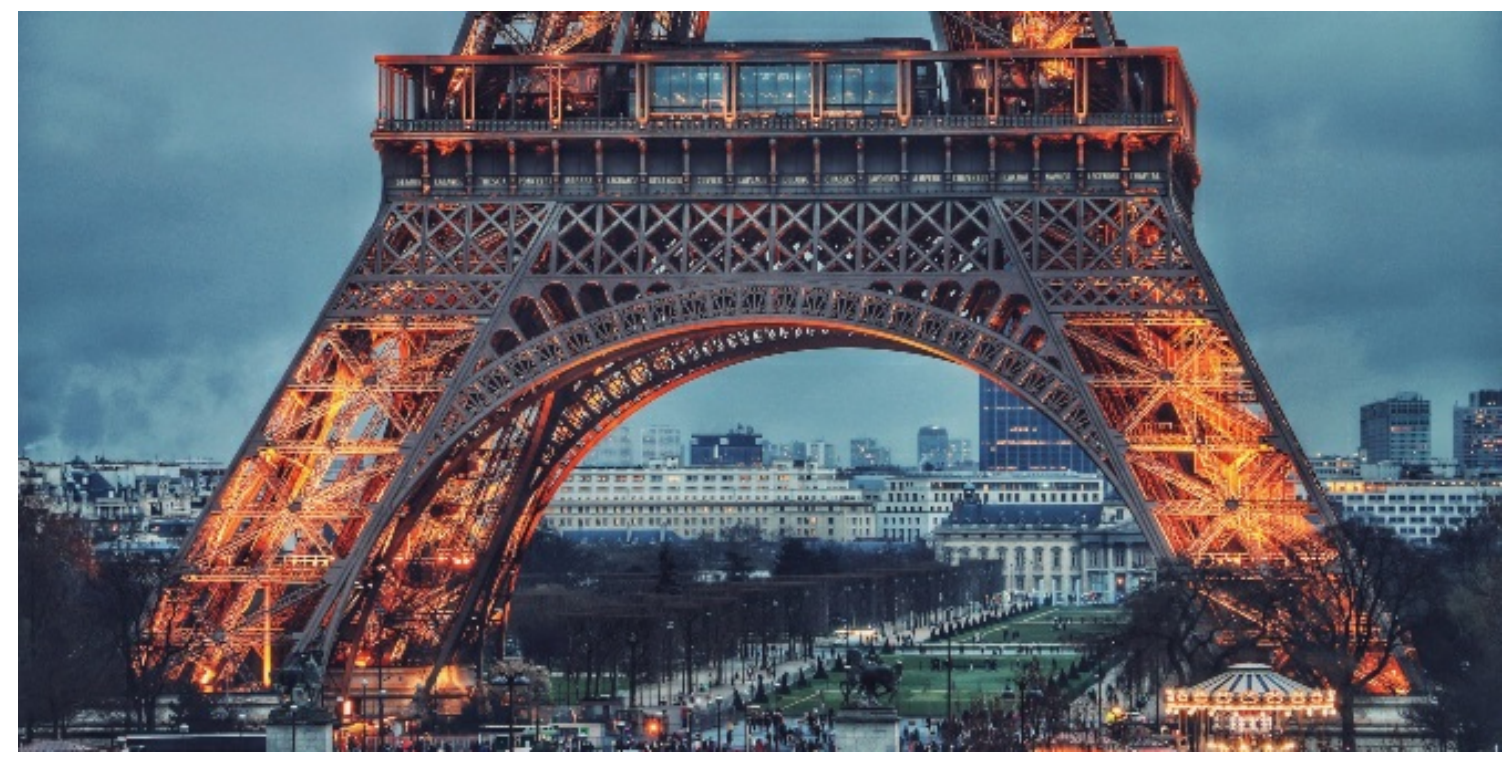

The COVID-19 crisis led to severe restrictions in mobility across borders, concerning both individuals and goods. Borders were closed, international travel made almost impossible, and final and intermediate goods were unable to get from one country to another. Massive disruptions of global value chains were caused by inputs not being manufactured due to lockdowns or not being delivered.

While the situation is improving, it is not clear what the long-run economic consequences of the pandemic are. Firms might, for instance, rely more on the production of inputs within national borders to be prepared for similar situations. Such hedging of risks might come at the expense of productivity, as most economists are aware. In addition, such a re-nationalisation or de-globalisation could interfere with monetary policy in the euro area and severely trouble the functioning of the monetary/currency union, which is not well known.

We show why this is the case in a recent research article. We use a dynamic macroeconomic currency union model to analyse how a currency union is affected by the interconnectedness of the countries and how this interacts with monetary policy. We analyse the model not only with rational expectations but also with a variety of behavioural expectations, as rational expectations have many times been attacked for their lack of realism. Which varieties of behavioural expectations we use is described further below - our main results hold up with behavioural and rational expectations alike.

\section{The importance of economic integration}

We show that the level of economic integration is crucial for the currency union to function. High economic integration in the model means that there are few barriers to trade, so that countries can and do trade a lot with each other. When countries trade a lot with each other, this means that the developments of inflation in one country matter relatively much for other countries. Thus, in a country currently in an economic downturn, inflation will be lower than in other countries. Therefore, prices in this country will become lower and its goods more competitive in other currency union countries. If the countries trade a lot with each other, the effect of the increased demand abroad can stabilise prices in the troubled country. While such a positive effect of trade in currency unions is well known, our article is the first to show this in a multi-country dynamic macroeconomic model with rational and behavioural expectations. 
Also, the level of economic integration needed for a currency union to function increases with the number of countries in the currency union. That is, while a currency union with only a few countries may still be fine with a moderate level of economic integration, a much higher level is needed in a currency union with many countries. There are certainly benefits to having many countries in a currency union (for instance no exchange rate risk for trade with all the involved countries or an advantage in becoming an international currency with borrowing privileges for the member countries), but it is important to know that large currency unions need a high degree of economic integration. However, the additional level of economic integration needed with each additional country decreases with the size of a currency union. When there are already many members, there is no need for much additional economic integration when a new member joins.

\section{The central bank cannot do enough: fiscal policy is needed}

Unfortunately, even well-conducted regular monetary policy - that is, appropriate changes in the monetary union interest rate - cannot improve the functioning of the union if economic integration is too low. The joint central bank could still do a lot of harm: too low interest rates in a boom or monetary policy that is not expansionary enough when the same negative shock hits all countries (such as COVID-19) would still be problematic. But even if the central bank reacts as best it can with symmetric measures, the union will always be in trouble if economic integration is too low.

The reason for that is that the central bank can never set an interest rate that is right for all countries. Some countries may be in a boom, while others are in an economic downturn. In such a case, the interest rate that is set for the currency union as a whole is too low for the countries in the boom and too high for the countries in the slump. This suggests that fiscal policy, which is conducted at the country level, is an indispensable macroeconomic stabilisation tool. Useful fiscal policy would not have to be directed by currency union authorities, but there would have to be enough leeway for the individual countries to conduct counter-cyclical fiscal policies. This could happen in coordination with the other countries or following joint rules at the union level, as long as these rules are not simple debt limits as the current EU rules (the countries must also be able to finance counter-cyclical fiscal policies - there are several ways to make sure that they are able to do so in times when additional spending is useful, including eurobonds or outright debt monetisation).

\section{Why use behavioural expectations? Realism and prediction performance}

Why is it important to use behavioural models of expectation formation? As the results are qualitatively similar under rational and behavioural expectations, wouldn't the model with rational expectations be enough?

First, that the results are qualitatively similar became only clear after analysing the model with both rational and behavioural expectations. This is by no means a trivial result, as rational and behavioural expectations often lead to (also qualitatively) very different results.

Second, rational expectations have been criticised so heavily for their lack of realism that it seems important not to base economic findings exclusively on them. Indeed, rational expectations place extraordinary demands on the ability of economic agents. Rational expectations require that agents know all equations determining economic outcomes and possess the computational ability to calculate the solutions of such equations, an impossible task in the real world.

While most economists acknowledge that people neither know the equations governing the economy nor engage in higher mathematics when making economic decisions, some macroeconomists believe that mistakes in expectation formation should somehow average out. Believing in such averaging out makes expectation formation a black box, completely eliminating any meaning from the so-called microfoundations that ground aggregate economic behaviour in individual decisions. It is in general also wrong, because expectations of different people are not uncorrelated.

The behavioural variants that we use go from a very simplistic model — where people naively use the last observation as expectation - to a sophisticated evolutionary learning model that performed well to describe individual expectations in other work (e.g., here and here). In this evolutionary learning model, people use relatively simple rules to forecast future variables, such as extrapolating past trends or thinking that variables will slowly return to a long-run average. However, agents are not stupid, they learn from the past: people rely more often on the forecasting rules that performed better in the recent past. 
We believe a good way to compare different models is to assess their prediction performance. Models that perform better out of sample are in general more convincing. While we do not perform a full estimation of all model parameters in our paper (which would be an interesting topic for an empirical paper), we compare the prediction performance of the models with rational and behavioural expectations on the basis of parameter estimates from other work. Figures 1 and 2 show the mean squared one-quarter-ahead prediction errors of the two types of models for inflation and for the output gap. As can be seen, both inflation and output gap are predicted much better by the behavioural model for all countries (relying on the evolutionary learning model for behavioural expectation formation).

Figure 1. Mean squared errors of one-quarter-ahead predictions for inflation

\section{Inflation Forecast Errors}

3

2.5

2

1.5

1

0.5

0

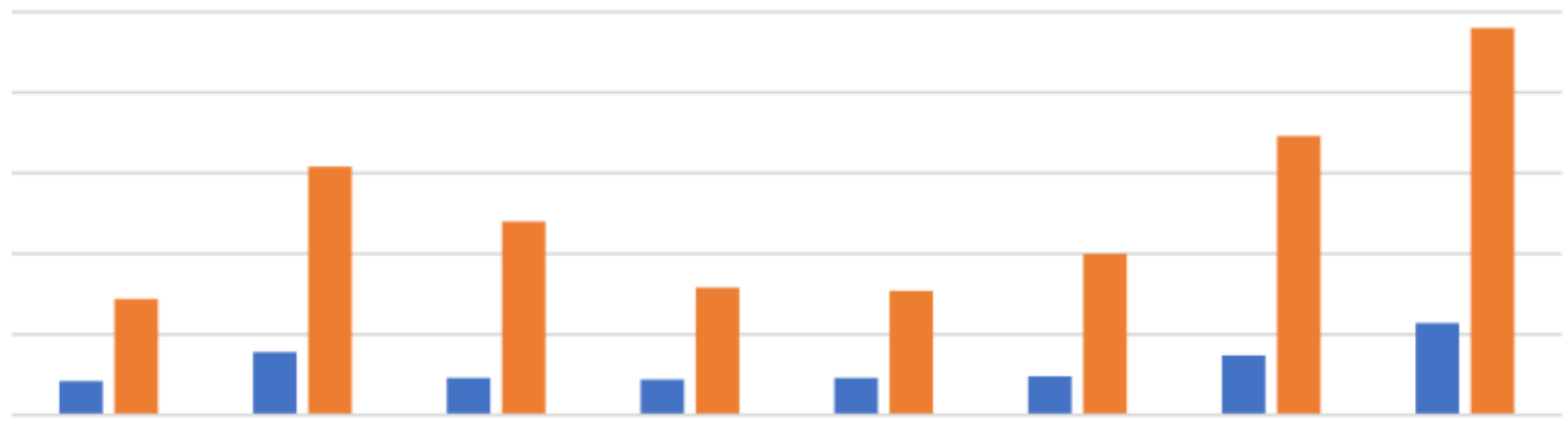

Austria Belgium Finland France Germany Italy Netherlands Spain

Behavioral Rational

Notes: The data used for Figures 1 and 2 are year-on-year percentage changes of the HICP for inflation and data as described here for the output gap (from 1999 to 2014).

Figure 2. Mean squared errors of one-quarter-ahead predictions for the output gap 


\section{Output Gap Forecast Errors}

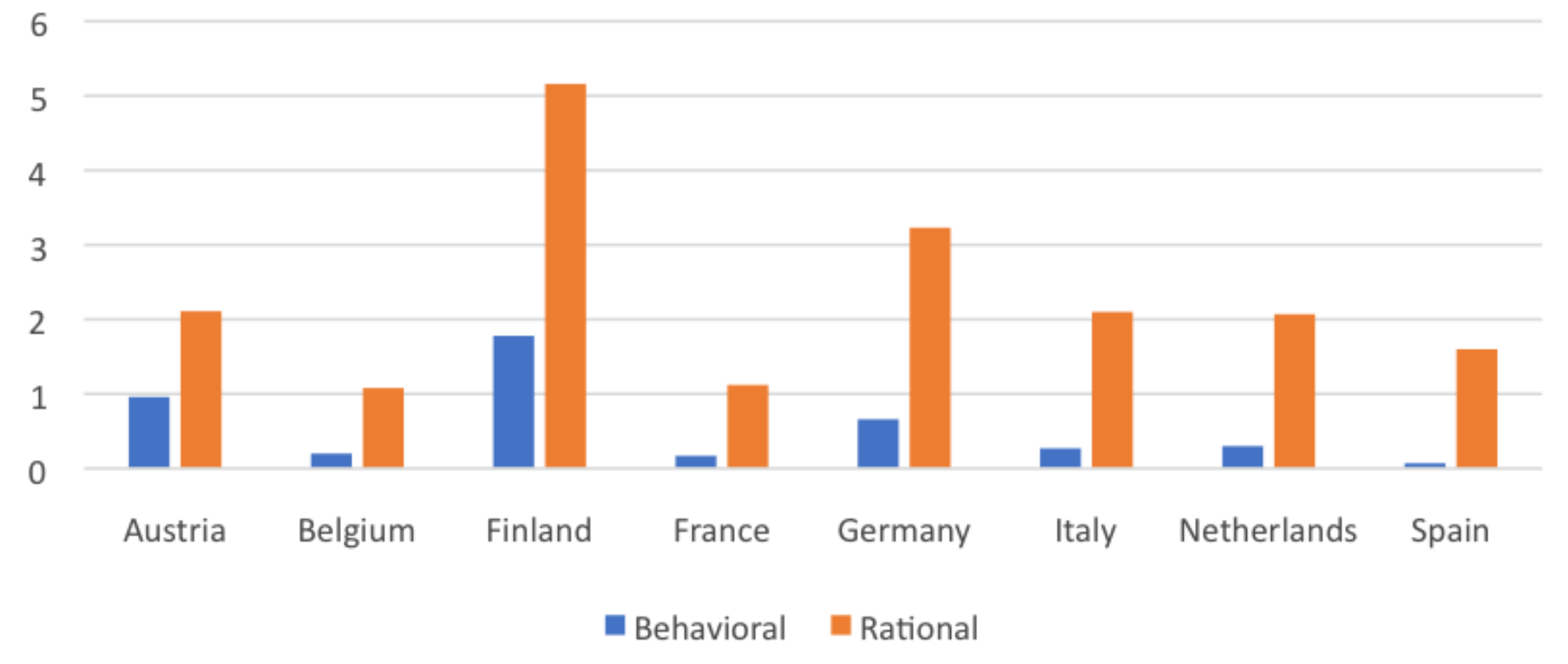

Notes: The data used for Figures 1 and 2 are year-on-year percentage changes of the HICP for inflation and data as described here for the output gap (from 1999 to 2014).

Notes:

- This blog post is based on The behavioral economics of currency unions: Economic integration and monetary policy (open access).

- The post expresses the views of its author(s), not the position of LSE Business Review or the London School of Economics.

- Featured image by Soroush Karimi on Unsplash

- When you leave a comment, you're agreeing to our Comment Policy

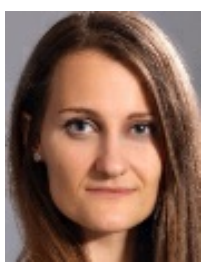

Akvile Bertasiute works at Euromonitor International. Before, she worked at the budget policy monitoring department of the National Audit Office of Lithuania. She obtained her bachelor's and master's degrees in econometrics from Vilnius University. Her fields of interest include behavioural macroeconomics and the role of fiscal policy in attaining macro stability.

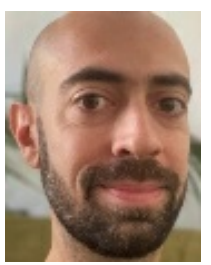

Domenico Massaro is an assistant professor at the Catholic University of Milan and research fellow at the Complexity Lab in Economics (CLE). His primary research interests are behavioural and experimental macroeconomics, complex systems and applied econometrics. More information can be found on his website.

Matthias Weber is an assistant professor at the University of St. Gallen's School of Finance. Before, he worked at the Bank of Lithuania and Vilnius University. His main research interests lie in the intersection of behavioural economics and macroeconomics, finance, and public economics. More information is available on his website. 


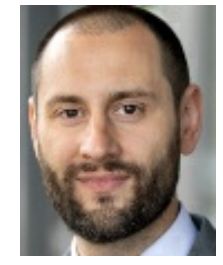

Date originally posted: $2020-07-01$

Permalink: https://blogs.Ise.ac.uk/businessreview/2020/07/01/deglobalisation-post-covid-19-could-spell-trouble-for-the-european-monetary-union/ Blog homepage: https://blogs.Ise.ac.uk/businessreview/ 